\title{
Análise da sensibilidade ambiental do litoral de Paraty (Estado do Rio Janerio, Brasil) a potenciais derramamentos de óleo
}

\section{Environmental sensitivity analysis of the coast of Paraty (State of Rio de Janeiro, Brazil) to potential oil spills}

\begin{abstract}
Análisis de la sensibilidad ambiental de la costa de Paraty (Estado de Rio de Janeiro, Brasil) a posibles derrames de petróleo
\end{abstract}

\author{
Ana Beatriz Pinheiro ${ }^{1}$ \\ Universidade Federal Fluminense, Brasil \\ André Luiz Carvalho da Silva ${ }^{2}$ \\ Universidade do Estado do Rio de Janeiro, Brasil
}

\begin{abstract}
Resumo
O presente estudo objetiva compreender o grau de sensibilidade ambiental do litoral de Paraty a potenciais eventos de derramamento de óleo e as consequências destes para os ecossistemas da região. Foram realizados 6 trabalhos de campo para a caracterização morfológica e sedimentar de seis praias de Paraty e mapeamento dos ambientes costeiros para a aplicação do Índice de Sensibilidade do Litoral (ISL) a eventos de derramamento de óleo. Como resultado, foram encontrados os
\end{abstract}

1 Doutoranda do Programa de Pós-graduação em Dinâmica dos Oceanos e da Terra da Universidade Federal Fluminense. Av. Gal. Milton Tavares de Souza, s/n - Campus da Praia Vermelha - Boa Viagem Niterói/RJ - Brasil - CEP: 24210-346. Endereço eletrônico: ana_pinheiro@id.uff.br

(iD https://orcid.org/0000-0003-3314-1718

2 Dr. Professor Adjunto do Departamento de Geografia da Faculdade de Formação de Professores da Universidade do Estado do Rio de Janeiro. Rua Dr. Francisco Portela, 1470 - Patronato. São Gonçalo, RJ. CEP $24435-$ 005. Endereço eletrônico: andrelcsilvageouerj@gmail.com (D) https://orcid.org/0000-0002-2912-7860 
seguintes ISL à poluição por óleo: ISL 1 e 2, atribuído aos costões rochosos de baixa a alta declividade respectivamente, localizados nas enseadas e ilhas; ISL 4, para as praias de Taquari, Prainha e São Gonçalinho; ISL 5, para as praias de Jabaquara (setor sul), Barra de Corumbê e São Gonçalo; ISL 6, para os depósitos de tálus e enrocamentos; ISL 10, correspondente as áreas de manguezais. O estudo da sensibilidade ambiental aponta para níveis distintos de vulnerabilidade deste litoral. A poluição por óleo em Paraty, tende a causar sérios danos aos diversos ecossistemas costeiros e marinhos, assim como às atividades turísticas e pesqueiras.

Palavras-chave: Sensibilidade ambiental; Poluição; Derramamento de óleo; Paraty-RJ.

\begin{abstract}
The present study aims to understand the degree of environmental sensitivity in the coastal region of Paraty (State of Rio de Janeiro, Brazil) to potential oil spill events and their consequences for the region's ecosystems. Six field evaluations were carried out for the morphological and sedimentary characterization of six beaches in Paraty, as well as mapping activities of the coastal environments in order to apply a coastal sensitivity index (CSI) to oil spill events. As a result, the following oil pollution CSIs were computed: CSI 1 and 2, attributed to low- and high-slope rocky shores, respectively, located along inlets and islands; CSI 4, for the beaches of Taquari, Prainha and São Gonçalinho; CSI 5, for the beaches of Jabaquara (south sector), Barra de Corumbê and São Gonçalo; CSI 6 , for talus deposits and rockfill and, CSI 10, corresponding to mangrove areas. The environmental sensitivity study points to the existence of different vulnerability levels along the coastal region that can be used to assess Paraty's oil pollution susceptibility which is of relevance from the perspective of marine ecosystems and the development of economic activities such as tourism and fishing.
\end{abstract}

Keywords: Environmental sensitivity; Pollution; Oil spills; Paraty (State of Rio de Janeiro, Brazil).

\title{
Resumen
}

El presente estudio tiene como objetivo comprender el grado de sensibilidad ambiental de la costa de Paraty a posibles eventos de derrames de petróleo y sus consecuencias para los ecosistemas de la región. Se llevaron a cabo seis trabajos de campo para la caracterización morfológica y sedimentaria de seis playas en Paraty y el mapeo de ambientes costeros para la aplicación del índice de sensibilidad costera (ISC) a los eventos de derrames de petróleo. Como resultado, se encontraron los siguientes ISCs a la contaminación por hidrocarburos: ISC 1 y 2 , atribuidos a costas rocosas de pendiente baja y alta, respectivamente, ubicadas en las entradas e islas; ISC 4, para las playas de Taquari, Prainha y São Gonçalinho; ISC 5, para las playas de Jabaquara (sector sur), Barra de Corumbê y São Gonçalo; ISC 6, para depósitos de talus y relleno rocoso y, ISC 10, correspondiente a áreas de manglares. El estudio de sensibilidad ambiental apunta a la existencia de diferentes niveles de vulnerabilidad a lo largo de la región útiles para evaluar la susceptibilidad de Paraty a la contaminación por petróleo, relevante desde la perspectiva de los ecosistemas marinos y el desarrollo de actividades económicas como el turismo y la pesca.

Palabras clave: Sensibilidad ambiental; Contaminación; Derrame de petróleo; Paraty (Estado de Rio de Janeiro, Brasil). 
Ana Beatriz Pinheiro, André Luiz Carvalho da Silva

Análise da sensibilidade ambiental do litoral de Paraty (Estado do Rio Janerio, Brasil) a potenciais derramamentos de óleo.

\section{Introdução}

A exploração de petróleo é uma das principais atividades econômicas no século XXI e os impactos socioambientais causados pelo transporte marítimo e terrestre de petróleo e derivados são cada vez danosos devido à ocorrência de eventuais derramamentos de óleo. Desastres com hidrocarbonetos são responsáveis pelo vazamento de milhares de litros de óleo nos oceanos e nos litorais, causando grandes impactos ambientais e econômicos nas áreas direta e indiretamente afetadas. Dentre as principais ocorrências de derramamento de óleo no Brasil pode-se ressaltar os acidentes ocorridos na Baía de Guanabara (RJ) e em Araucária (PR), ambos no ano 2000; no Rio Caceribu (RJ), em 2005; no Porto de Paranaguá (PR), em 2004; e em centenas de praias do litoral do nordeste, no ano de 2019, afetando uma área de cerca de 2.700 quilômetros de litoral. No mundo destacam-se os desastres ocorridos no Golfo do México (EUA), em 2010; na Itália e em Angola, no ano de 1991; na África do Sul e no Golfo Pérsico, em 1983 (Baptista, 2017), entre outros.

Os ambientes costeiros apresentam uma capacidade de regeneração em resposta a desastres ambientais que pode variar bastante de acordo com o tipo, intensidade e forma de ocorrência de um evento qualquer (Muler et al., 2011). A recuperação de um ambiente afetado por um derramamento de óleo pode ser rápida ou extremamente lenta, dependendo das características morfológicas, sedimentares e da hidrodinâmica de cada seguimento do litoral (MMA, 2002; Souza, 2007; Boulhosa \& Souza Filho, 2009; Muler et al., 2011; Rodrigues \& Souza-Filho, 2012). Além disso, a influência das condições de mar, a direção das correntes e o clima de ondas geram variações temporais na sensibilidade dos ambientes costeiros (Souza, 2007; Boulhosa \& Souza Filho, 2009). A esses processos, somam-se os efeitos das marés e das ressacas produzidas pelas tempestades (Davis Jr, 1985; Davidson-Arnott, 2010). A combinação destes diferentes processos e a forma com que eles ocorrem junto à costa são diretamente responsáveis pelo transporte de poluentes na direção dos litorais, alcançando e contaminando as áreas de costões, baías, manguezais e praias. O conhecimento dessas características é fundamental para a determinação do grau do impacto, da permanência e comportamento do óleo derramado, ao longo do litoral (Castro et al., 2003; MMA, 2002). Para que sejam reconhecidos e diferenciados os níveis de impactos ocasionados por derramamento de 
óleo no litoral, foi estabelecido o Índice de Sensibilidade do Litoral (ISL), que foi desenvolvido pela Organização Marítima Internacional (IMO) e pela Administração Atmosférica e Oceânica Nacional (NOAA) dos Estados Unidos (NOAA, 2007). No Brasil, este índice foi adaptado pelo Ministério do Meio Ambiente (MMA, 2002) e vem sendo amplamente utilizado na caracterização da sensibilidade ambiental em diversas áreas costeiras (MMA, 2002; Gherardi et al., 2008; Poletto \& Batista, 2008; Boulhosa \& Souza-Filho, 2009; Cunha, 2009; Silva et al., 2009; Muler et al., 2011; Romero, 2009; Perinotto et al., 2010; Rodrigues \& Souza-Filho, 2012; Martins et al., 2013; Gil-Agudelo et al., 2015; Pinheiro, 2018; Baptista et al., 2019, entre outros). O ISL possui uma classificação que varia em uma escala de 1 a 10, sendo 1 para os ambientes menos sensíveis e 10 para os ambientes mais sensíveis à poluição causada por derramamento de óleo (MMA, 2002).

A presença de óleo nos oceanos e litorais tende a causar a destruição de habitats costeiros, através da contaminação, intoxicação e asfixia de animais marinhos e aves, dentre outros danos. Os impactos econômicos consistem principalmente na diminuição da atividade pesqueira, sobretudo a tradicional, além da inviabilidade de atividades de lazer na área, afetando as atividades turísticas, e a economia local. As atividades turísticas tem desempenhado um papel cada vez mais relevante na intensificação dos usos na zona costeira, principalmente nas últimas décadas (Moraes, 2007), como ocorre em Paraty. A poluição por óleo pode interferir no comportamento dos fatores ambientais, sociais e econômicos, gerando então impactos que podem ser sentidos de imediato ou a médio e longo prazo. Este trabalho objetiva identificar a sensibilidade ambiental do litoral de Paraty (RJ) (Figura 1) frente um eventual desastre causado por derramamento de óleo. Para tal, foram utilizados dados de morfologia e sedimentação de algumas praias no litoral (Pinheiro, 2018) e relacionados à hidrodinâmica costeira, o que permitiu a aplicação do Índice de Sensibilidade do Litoral (ISL) a derramamento de óleo, proposto pelo Ministério do Meio Ambiente (MMA, 2002).

\section{Área de estudo}

O município de Paraty (Figura 1) está localizado a leste de Angra dos Reis (RJ) e a oeste de Ubatuba (SP). O litoral possui uma variedade de ilhas e praias abrigadas na borda oeste da Baía da Ilha Grande e praias 
oceânicas, todas cercadas pela Mata Atlântica. Essa região é caracterizada pela presença das escarpas da Serra do Mar formando a linha de costa, com uma sucessão de pequenas enseadas e estreitas planícies costeiras flúviomarinhas (Medeiros, 2006). Esse trecho do litoral sul fluminense apresenta muitas praias de enseadas, do tipo pocket beach, geralmente de pouca extensão, separadas pelo embasamento cristalino (Pranzini et al., 2013; Bowman et al., 2014). A geologia de grande parte de Paraty é dominada por montanhas e morros com vertentes que chegam ao mar, formadas por granitos e gnaisses, onde a vegetação chega próximo ao nível d'água cobrindo praticamente toda a rocha, exceto os grandes campos de blocos que ficam dentro d'água (Faria, 2018). Este litoral apresenta diferenças significativas quanto à direção de incidência de ondas, morfologia e materiais que formam os ambientes litorâneos dentro da Baia da Ilha Grande. O transporte de sedimentos em direção às praias no interior da baía é influenciado pela presença da Ilha Grande, que interfere diretamente na propagação de ondas devido a configuração da linha de costa. No entanto, ondas provenientes de sul a sudeste possuem uma maior facilidade de entrada na baía, tornando-a mais sensível as tempestades vindas dessas direções (Godoi et al., 2011; Muehe et al., 2006). Segundo Godoi et al. (2011), a situação típica na Baía de Ilha Grande é de ondas de baixa energia entrando sem causar nenhum tipo de dano. No entanto, durante a ocorrência de ressacas, as ondas tendem a atingir regiões que são normalmente protegidas, podendo causar impactos nas estruturas costeiras. Esses danos podem ser ainda maiores quando ondas de tempestades ocorrem associadas à maré de sizígia.

O município de Paraty tem sua História marcada pelo Período Colonial Brasileiro, por ter sido sede do mais importante porto exportador de ouro do Brasil no século XVIII. Atualmente, Paraty foi reconhecida como patrimônio cultural e natural da humanidade pela UNESCO, juntamente com a Ilha Grande. De acordo com Benchimol (2007) e Padilha (2016), a principal atividade econômica do município é pautada no turismo, que corresponde a cerca de $80 \%$ da fonte de renda, seguida pela atividade pesqueira. Essa pequena cidade litorânea atrai um grande número de visitantes de várias partes do Brasil e do mundo. Além de possuir um importante Centro Histórico, conta também com um calendário repleto de eventos e festivais culturais, além de ser um destino muito procurado pelas belas praias, ilhas, cachoeiras, trilhas cercadas pela Mata Atlântica 
Figura 1. Localização do litoral abrigado de Paraty e das praias caracterizadas para o presente estudo.

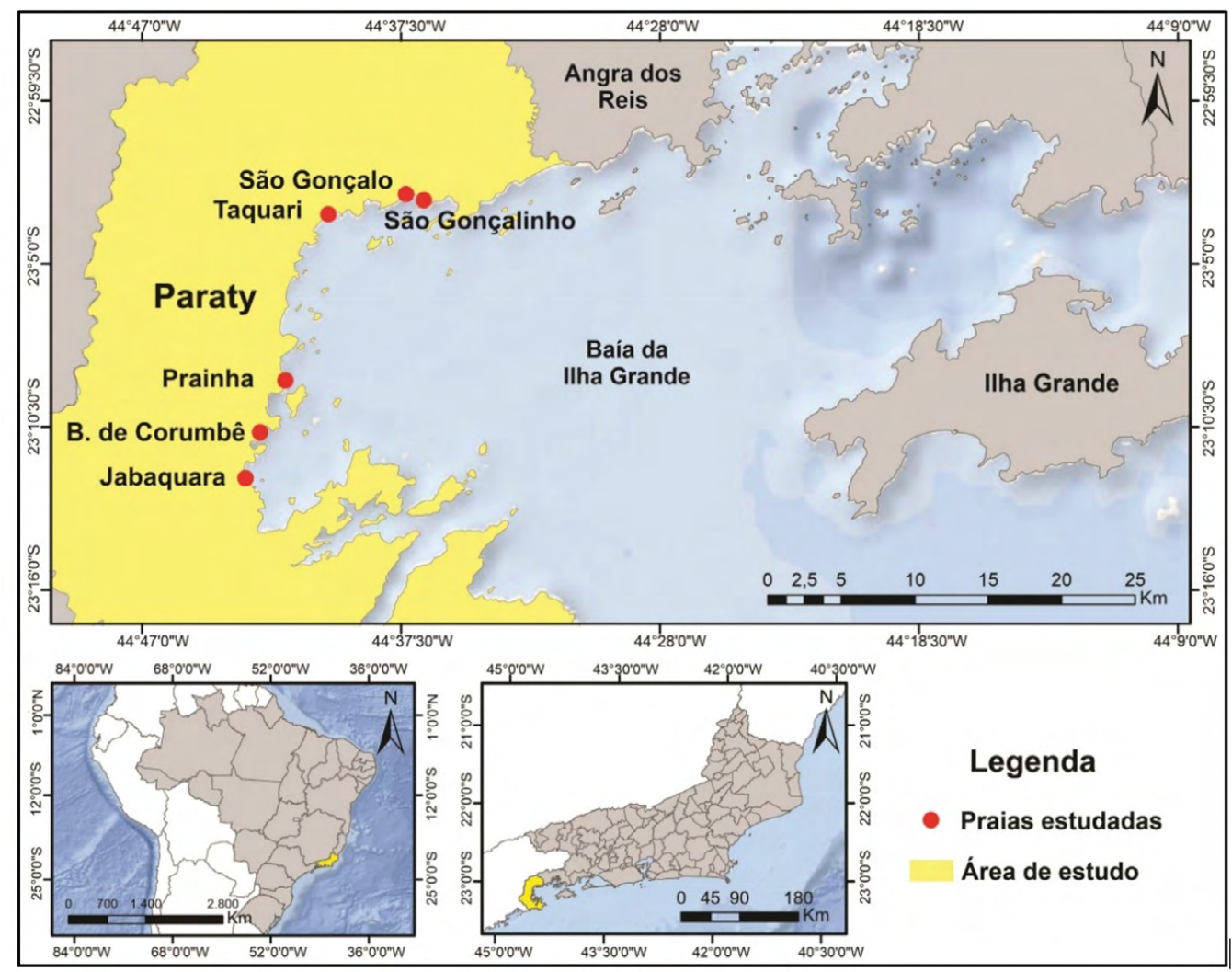

Fonte: Elaboração própria.

e comunidades tradicionais (caiçaras quilombolas e indígenas). Esse litoral apresenta diversas Unidades de Conservação, que de que acordo com Benchimol (2007), contribui para a preservação da alta diversidade e relevância ambiental desse litoral. Apesar da presença da rica biodiversidade e geodiversidade, os estudos realizados nesta parte do litoral fluminense ainda são pouco representativos quando comparados a outras áreas.

A área de estudo está inserida em um trecho do litoral brasileiro pertencente à Bacia de Santos (Mohriak, 2003), que tem na exploração de petróleo uma das principais atividades econômicas do Estado do Rio de Janeiro. 
Os impactos socioambientais causados pelo transporte marítimo e terrestre de petróleo e derivados são cada vez mais frequentes devido à ocorrência de eventuais derramamentos de óleo. Com o crescimento das atividades inerentes à extração de petróleo nesta Bacia de Santos, ligadas à exploração da camada Pré-Sal; bem como, a existência do Terminal Petrolífero da Baía da Ilha Grande (TEBIG), localizado a cerca de $40 \mathrm{~km}$ de Paraty; e o aumento do tráfego de embarcações turísticas e industriais na Baía da Ilha Grande, cresce a preocupação quanto à ocorrência de eventuais desastres ambientais associados a derramamento de óleo, principalmente quando se considera a grande importância cultural e natural da região e a relevância das atividades ligadas ao turismo e a pesca para a população nessas áreas.

Além disso, desastres dessa natureza já ocorreram na região em função das atividades realizadas no TEBIG, como os que aconteceram em 2000 e 2002, onde foram derramados 4 e 16 mil litros de óleo, respectivamente, ambos causados por acidentes com navios (Oliveira, 2003; Oliveira $\&$ Meyer, 2006). Mais recentemente, nos anos de 2015 e 2016 ocorreram novos vazamentos durante operações de transferência de óleo e abastecimento de combustíveis.

A capacidade do litoral de responder a desastres ambientais causados por derramamentos de óleo em inúmeras escalas é, até então, pouco conhecida. Diante desse cenário torna-se necessária a realização de estudos que visem contribuir com conhecimentos acerca da sensibilidade ambiental deste litoral diante da possibilidade iminente e crescente de desastres, sobretudo para a preservação dos ecossistemas costeiros e para a manutenção das atividades desenvolvidas nesse litoral.

\section{Material e métodos}

O mapeamento do litoral de Paraty objetivou identificar os diversos ambientes (praias, manguezais, costões rochosos, dentre outros) presentes na área de estudo, para posterior classificação e representação cartográfica do Índice de Sensibilidade do Litoral (ISL) à poluição por óleo (Tabela 1). As características relativas à morfologia e sedimentação das praias foram obtidas a partir de estudos realizados por Pinheiro (2018); para a caracterização das condicionantes oceanográficas são considerados estudos realizados por Godoi et al. (2011), Fragoso (1999) e Mahiques (1987). 


\section{Tabela 1. Classificação do Índice de Sensibilidade do Litoral. O código RGB (em inglês Red, Green e Blue) constitui o sistema de cores aditivas aplicadas na classificação do ISL.}

\begin{tabular}{|c|c|c|c|c|c|}
\hline \multirow{2}{*}{ Cor } & \multirow{2}{*}{ Índice } & \multicolumn{3}{|c|}{ Código } & \multirow{2}{*}{ Tipos de costa } \\
\hline & & $\overline{\mathbf{R}}$ & $\mathbf{G}$ & $\overline{\mathbf{B}}$ & \\
\hline & ISL 1 & 119 & 38 & 105 & $\begin{array}{l}\text { - } \text { Costões rochosos lisos, de alta declividade, expostos } \\
\text { - } \text { Ealésias em rochas sedimentares expostas } \\
\text { Estruturas artificiais lisas (paredões marítimos artificiais), expostas }\end{array}$ \\
\hline & ISL 2 & 174 & 153 & 191 & $\begin{array}{l}\text { - Costões rochosos lisos, de declividade média a baixa, expostos } \\
\text { Terraços ou substratos de declividade média, expostos (terraços ou plata- } \\
\text { forma de abrasão, terraço arenítico exumado bem consolidado, etc.) }\end{array}$ \\
\hline & ISL 3 & 0 & 151 & 212 & $\begin{array}{l}\text { - Praias dissipativas de areia média a fina, expostas } \\
\text { - Faixas arenosas contíguas à praia, não vegetadas, sujeitas à ação de res- } \\
\text { sacas (restingas isoladas ou múltiplas, feixes alongados de restingas tipo } \\
\text { "long beach") } \\
\text { - Escarpas e taludes íngremes (formações do grupo Barreiras e Tabuleiros } \\
\text { - Litorâneos), expostos } \\
\text { Campos de dunas expostas }\end{array}$ \\
\hline & ISL 4 & 146 & 209 & 241 & $\begin{array}{l}\text { - Praias de areia grossa } \\
\text { - Praias intermediárias de areia fina a média, expostas } \\
\end{array}$ \\
\hline & ISL 5 & 152 & 206 & 201 & $\begin{array}{l}\text { - Praias mistas de areia e cascalho, ou conchas e fragmentos de corais } \\
\text { - Terraço ou plataforma de abrasão de superfície irregular ou recoberta de } \\
\text { vegetação } \\
\text { - Recifes areníticos em franja }\end{array}$ \\
\hline & ISL 6 & 0 & 149 & 32 & $\begin{array}{l}\text { - Praias de cascalho (seixos e calhaus) } \\
\text { - Costa de detritos calcários } \\
\text { - Eepósito de tálus } \\
\text { - Plataformentos ("rip-rap", guia corrente, quebra-mar) expostos } \\
\text { formes e porosas) }\end{array}$ \\
\hline & ISL 7 & 214 & 186 & 0 & $\begin{array}{l}\text { - Planície de maré arenosa exposta } \\
\text { - Terraço de baixa-mar }\end{array}$ \\
\hline & ISL 8 & 225 & 232 & 0 & $\begin{array}{l}\text { - Escarpa / encosta de rocha lisa, abrigada } \\
\text { - Escarpa / encosta de rocha não lisa, abrigada } \\
\text { - Escarpas e taludes íngremes de areia, abrigados } \\
\text { Enrocamentos ("rip-rap" e outras estruturas artificiais não lisas) abrigados }\end{array}$ \\
\hline & ISL 9 & 248 & 163 & 0 & $\begin{array}{l}\text { - Planície de maré arenosa / lamosa abrigadas e outras áreas úmidas costei- } \\
\text { ras não vegetadas } \\
\text { - Terraço de baixa-mar lamoso abrigado } \\
\text { - Recifes areníticos servidos de suporte para colônias de corais }\end{array}$ \\
\hline & ISL 10 & 214 & 0 & 24 & $\begin{array}{l}\text { - } \text { Deltas de barras de rios vegetadas } \\
\text { - Brraços alagadiços, banhados, brejos, margens de rios e lagoas } \\
\text { bro ou sabro ou de água salgada, com vegetaçãa adaptada ao meio salo- } \\
\text { - Marismas } \\
\text { - Manguezal (mangues frontais e mangues de estuários) }\end{array}$ \\
\hline
\end{tabular}

Fonte: MMA (2002).

Os mapas de ISL foram confeccionados através do programa ArcGis 10.1 e foram adquiridos por meio da base de dados do Instituto Brasileiro de Geografia e Estatística (IBGE). Neste sentido, utilizou-se ortomosaicos com escala de 1:25.000, que integram o projeto RJ-25, formado por 
fotografias aéreas coloridas ortorretificadas, com projeção UTM e referencial geodésico WGS 1984. Foram consideradas as Especificações e normas técnicas para a elaboração de cartas de sensibilidade ambiental para derramamentos de óleo (Tabela 1; MMA, 2002), com base nas características geológicas, geomorfológicas, sedimentares e a dinâmica do litoral estudado, fundamentais para a determinação do grau do impacto, o tempo de permanência, o comportamento do óleo derramado e o transporte de sedimentos (Castro et al., 2003; Rocha, 2009; Romero, 2009; MMA, 2002).

Os ambientes geomorfológicos foram mapeados por meio da geração de linhas, polígonos e pontos. As praias classificadas quanto ao ISL são àquelas estudadas por Pinheiro (2018); as demais não foram classificadas devido à ausência de dados geomorfológicos. Os demais ambientes costeiros foram classificados com base nos levantamentos de campo e a partir das imagens utilizadas para o mapeamento.

\section{Resultados e discussão}

Sensibilidade do litoral de Paraty a derramamento de óleo

$\mathrm{O}$ litoral de Paraty exibe uma sensibilidade ambiental à poluição por derramamento de óleo bastante variada. Essa diversidade é o resultado de uma geomorfologia e geologia marcada pela presença de áreas rochosas com diferentes declividades, praias com morfologias e sedimentos distintos (areias e cascalhos) e manguezais.

A partir disso foram estabelecidos os seguintes índices de sensibilidade do litoral a derramamento de óleo: ISL 1, atribuído aos costões rochosos expostos de alta declividade; ISL 2, que corresponde as áreas rochosas expostas de média a baixa declividade; ISL 4, que compreende as praias abrigadas de areia fina a média; (4) ISL 5, para praias mistas de areia e cascalhos; (5) ISL 6, para os depósitos de tálus e enrocamentos; (6) ISL 10, caracterizados por terraços alagadiços, brejos e manguezais (Figuras 2 e 3 ).

O ISL 1 e 2, em ambos os casos, aplica-se a áreas de costões rochosos com características semelhantes. A grande diferença entre esses índices refere-se basicamente a declividade apresentada pelas superfícies rochosas: consideradas como de ISL 1 , quando exibem mais de $30^{\circ}$ de inclinação; e de ISL 2, para declividades inferiores a $30^{\circ}$ (Tabela 1; MMA, 2002). Em superfícies rochosas, de ambos os casos, normalmente não ocorre penetração de óleo, que tende a permanecer por pouco tempo no ambiente. 
A depender do tipo de óleo, a remoção nas superfícies rochosas tende a ocorrer de forma rápida e natural por meio da ação das ondas (CETESB, 2007), o que não impede a contaminação de algas e demais animais e vegetais marinhos. O ISL 1 foi atribuído as áreas de enseadas que abrigam costões com alta declividade, superior a $30^{\circ}$ (Figuras 2 e $3 \mathrm{~A}$ ); o ISL 2 corresponde às ilhas e costas rochosas com declividade baixa a moderada (inferior a $30^{\circ}$ ), presentes ao longo de todo o litoral de Paraty (Figura 3B).

Os costões rochosos, segundo Faria (2018) possuem uma dinâmica própria, pois são ambientes com substrato fixo e impermeável; quando apresentam altas declividades, as ondas tendem a se chocar, arremessando água em várias direções. Mesmo em se tratando dos ambientes menos sensíveis (ISL 1 e 2) à contaminação por óleo, o efeito splash causado pela colisão das ondas com o costão pode arremessar água contaminada com óleo para as faixas superiores dessas rochas. Essas áreas geralmente são de difícil acesso e são, consequentemente, lavadas pela ação das ondas e marés, o que pode causar a contaminação dos ecossistemas presentes nos costões.

Figura 2. Mapa do Índice de Sensibilidade do Litoral de Paraty.

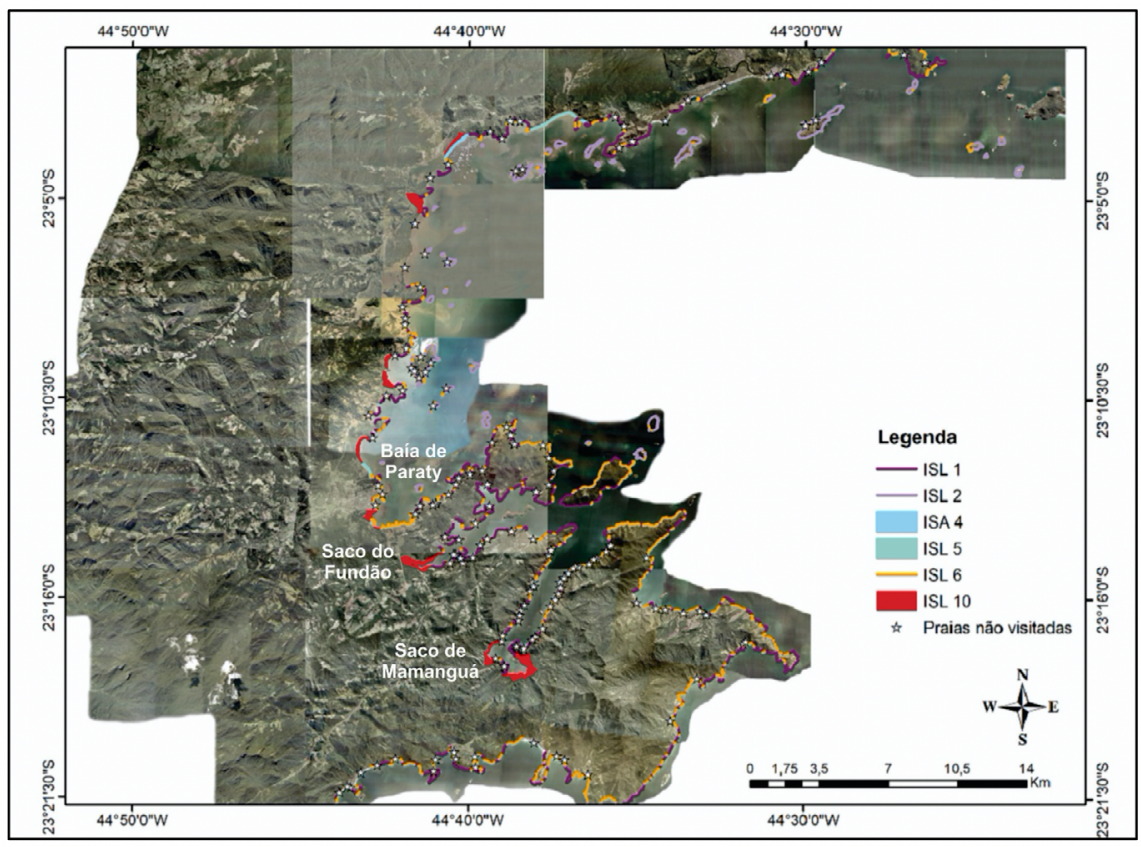

Fonte: Elaboração própria. 
Ana Beatriz Pinheiro, André Luiz Carvalho da Silva

Análise da sensibilidade ambiental do litoral de Paraty (Estado do Rio Janerio, Brasil) a potenciais derramamentos de óleo.

Os ambientes litorâneos classificados com o ISL 4 são representados por praias expostas com areias grossas e praias abrigadas de areia fina a média; apresentam em geral declividade entre 3 e 10 graus de inclinação; substratos moderadamente permeáveis, o que tende a facilitar a penetração do óleo (Tabela 1; MMA, 2002). As praias abrigadas de areia fina a média (com diâmetro dos grãos entre 0,062 a $1 \mathrm{~mm}$, conforme MMA, 2002), têm características parecidas àquelas consideradas como de ISL 3, porém, são mais sensíveis por estarem abrigadas e por possuírem menor grau de exposição à incidência de ondas e as oscilações de maré. Os ambientes

Figura 3. Exemplos de ambientes relacionados aos diversos ISL estabelecidos ao longo do litoral de Paraty.

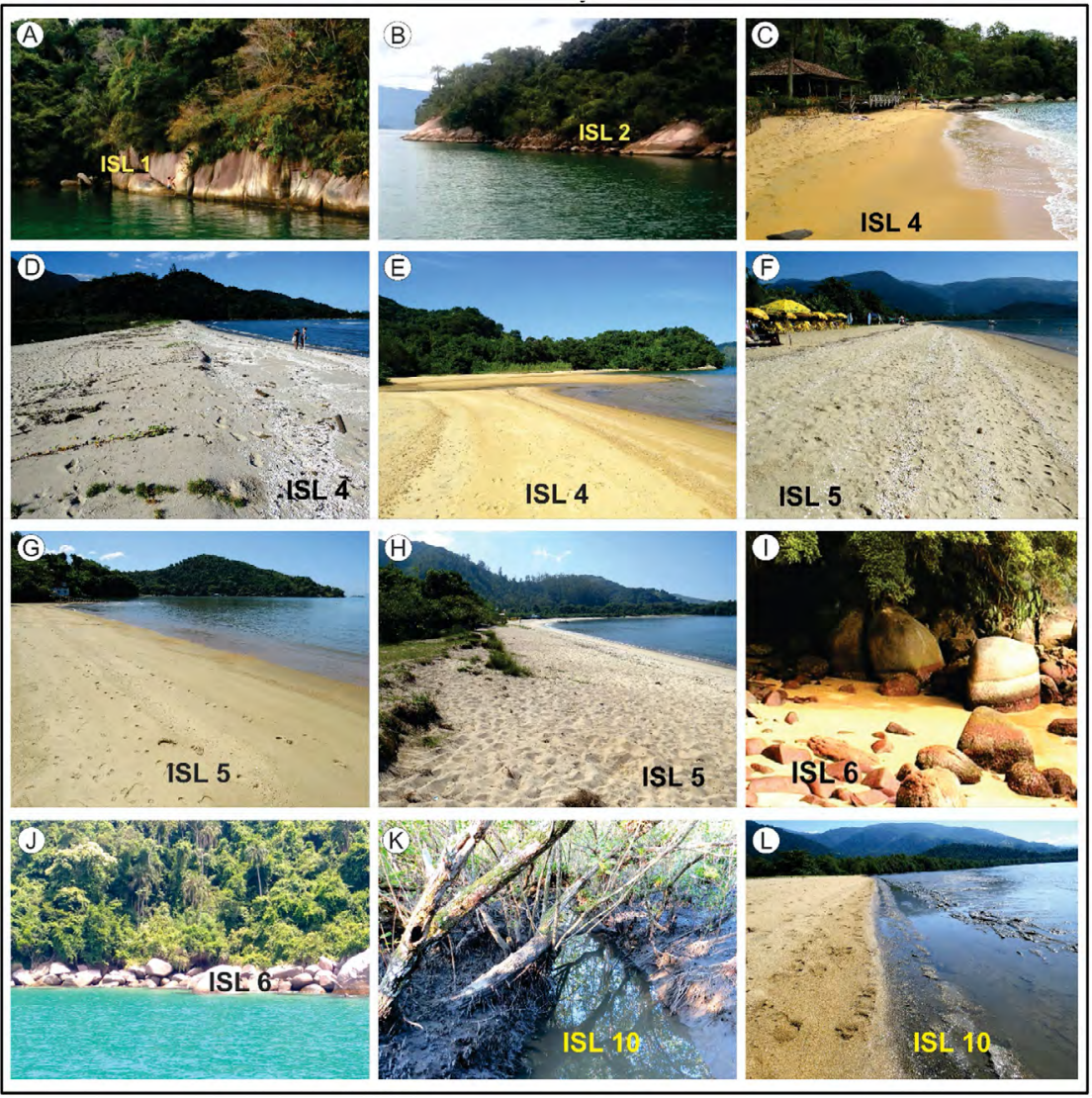

Fotos: André Silva, 2016. 
classificados com o ISL 4 no litoral de Paraty correspondem as praias de Prainha (Figura 3C e 6), Taquari (Figura 3D e 5) e São Gonçalinho (Figuras $3 \mathrm{E}$ e 4). A grande maioria dessas praias estão confinadas entre afloramentos rochosos, com exceção da praia de Taquari, que é mais extensa e exibe uma morfologia em pontal (Figura $3 \mathrm{C}$ ).

As praias confinadas são igualmente reconhecidas no litoral da Ilha Grande (Gralato, 2016; Silva et al., 2020) e de Paraty (Pinheiro, 2018) e na Baía de Guanabara (Amador, 1997; Silva et al., 2016), no estado do Rio de Janeiro; nas Baías de Paranaguá e de Tijucas, em Santa Catarina (Longarete et al., 2016; Rosa \& Borzone, 2008). As praias confinadas (pocket beaches) apesar de serem protegidas por promontórios, ilhas ou baías, também podem ser expostas a ondas de alta energia, devido a baixa dissipação de um fundo marinho geralmente inclinado e são bastante sensíveis a eventos de tempestade (Bowman et al 2014; Pranzini et al 2013).

As praias aqui classificadas apresentam, em geral, uma baixa dinâmica, sem grandes alterações morfológicas entre as estações do ano; caracterizam-se essencialmente por um baixo transporte de sedimentos entre a praia e as áreas adjacentes e são em geral orientadas perpendicularmente à direção de incidência das ondas (Pinheiro, 2018).

Algumas áreas no litoral de Paraty, como em Taquari, exibem uma dinâmica mais acentuada, relacionada a localização geográfica e orientação das praias, sujeitas a uma maior exposição à incidência de ondas de tempestades que entram na baía (Pinheiro, 2018).

Nesse trecho costeiro, as ondas de tempestade transpõem a barreira (processo de overwash) durante eventos de maior energia, depositando sedimentos no reverso, formando depósitos de leques de arrombamento ou de sobrelavagem (washover fans). Neste caso, a transposição por ondas de tempestade, com potencial contaminação de áreas à retaguarda do cordão litorâneo, tende a causar impactos severos nas comunidades bióticas e a dificuldade da limpeza se agravada pela tendência dos equipamentos misturarem ainda mais o óleo com os sedimentos (MMA, 2002). Nas praias classificadas com ISL 4, a penetração do óleo tende a alcançar até cerca de $25 \mathrm{~cm}$ de profundidade; há possibilidade de sequência de estratos com e sem contaminação, o que dificulta a limpeza e exige o manuseio de grande volume de sedimentos. 
Ana Beatriz Pinheiro, André Luiz Carvalho da Silva

Análise da sensibilidade ambiental do litoral de Paraty (Estado do Rio Janerio, Brasil) a potenciais derramamentos de óleo.

Figura 4. Mapa de Índice de Sensibilidade Ambiental do Extremo Norte.

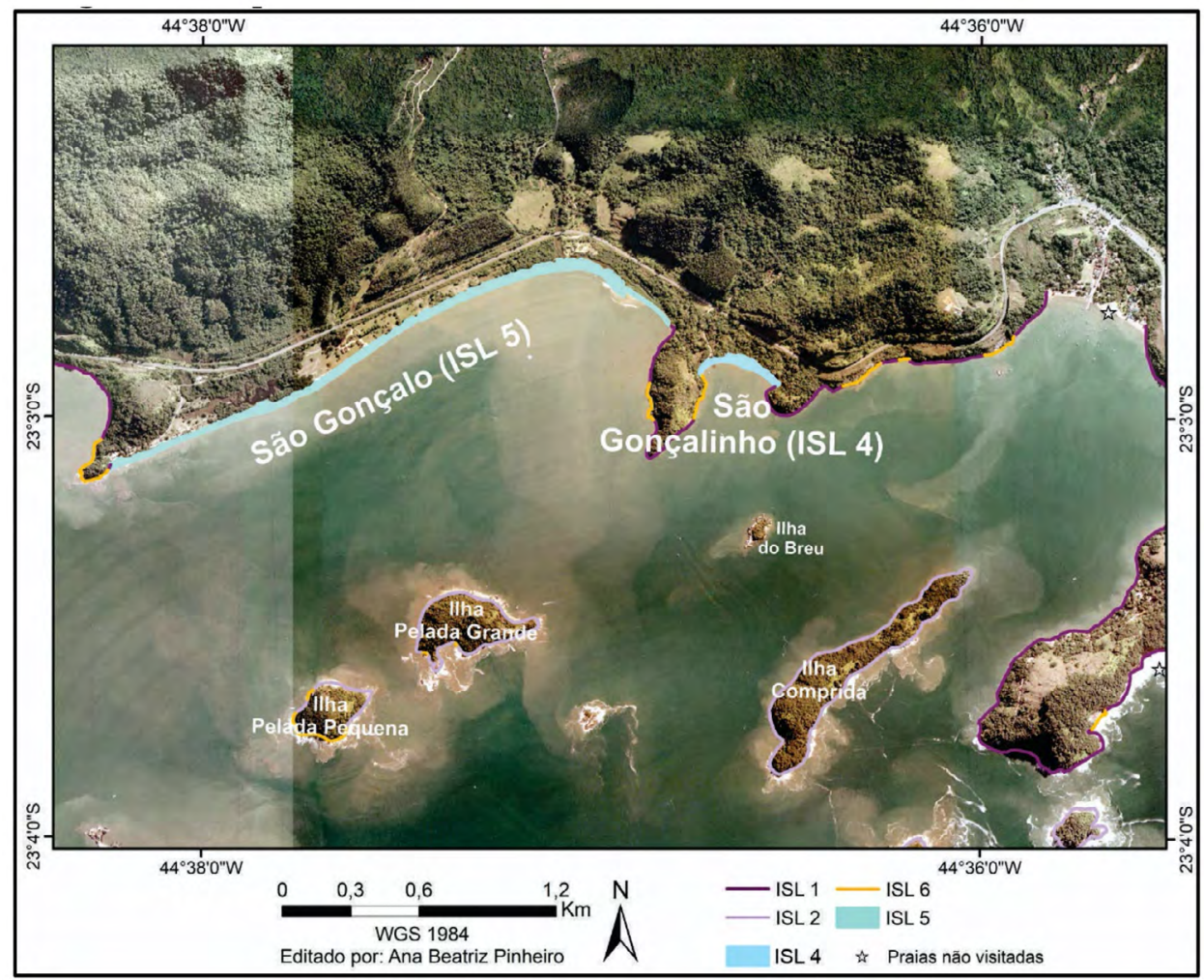

Fonte: Elaboração própria.

As praias classificados com o ISL 5 são compostas por areia e cascalho ( $\geq 20 \%$ ), conchas ou fragmentos de corais; geralmente expostas a diferentes níveis de energia das ondas e das correntes de maré; apresentam declividade entre 8 e 15 graus na zona de intermaré; elevada mobilidade dos sedimentos, principalmente durante e após a ocorrência de tempestade (Tabela 1; MMA, 2002).

Em Paraty, as áreas representadas pelo ISL 5 correspondem a setor sul da praia de Jabaquara (Figuras 3F e 7), Barra de Corumbê (Figuras 3G e 7) e São Gonçalo (Figuras $3 \mathrm{H}$ e 4). A percolação do óleo nesses ambientes pode atingir até $50 \mathrm{~cm}$ de profundidade, evidenciando uma elevada permeabilidade do óleo nos sedimentos da praia. Tal característica tende a 
Figura 5. Mapa de Índice de Sensibilidade Ambiental do Setor Norte.

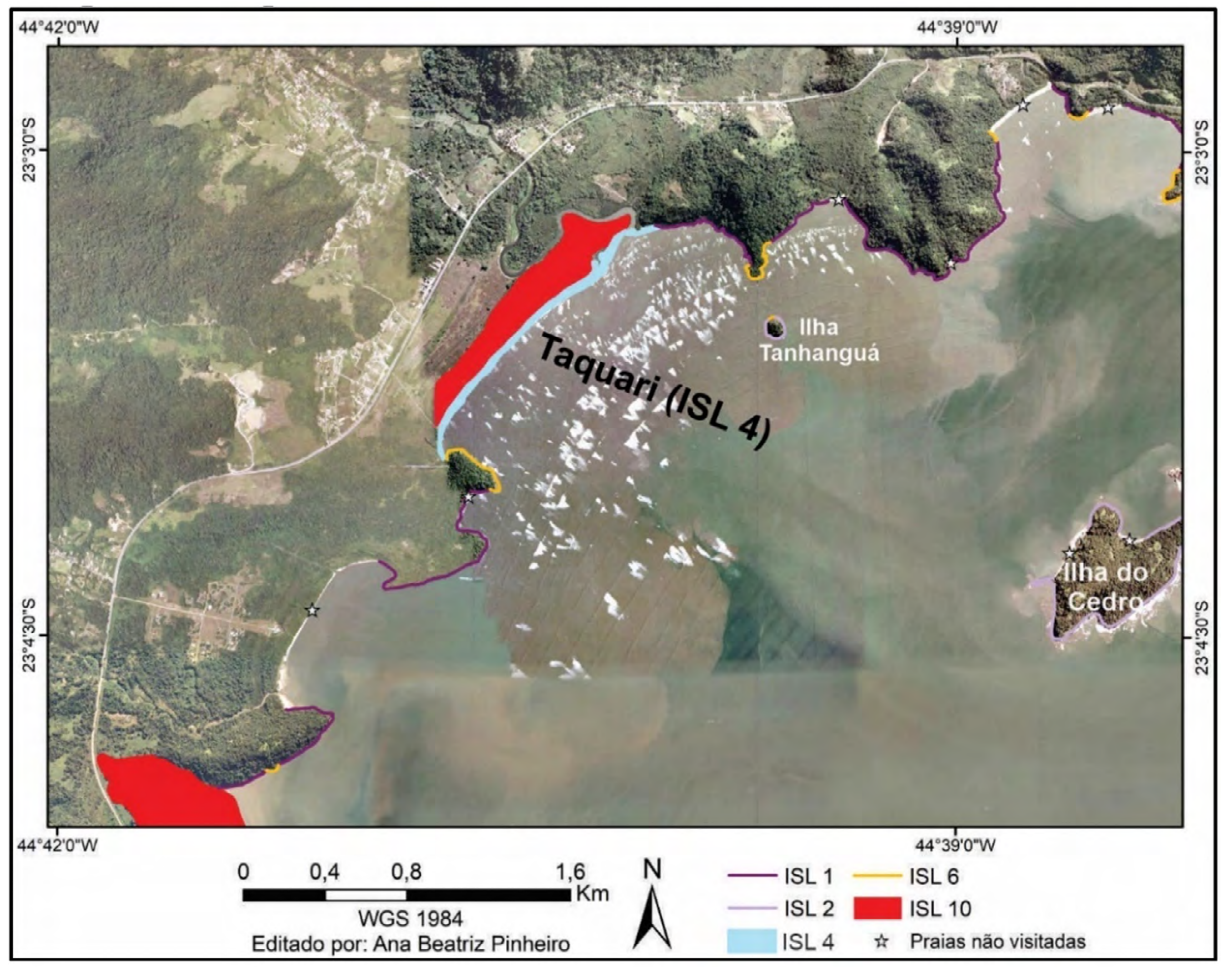

Fonte: Elaboração própria.

dificultar a limpeza da praia, podendo causar até erosão caso seja removida uma quantidade expressiva de sedimentos. A persistência do óleo pode ser alta se houver soterramento ou retenção em irregularidades do substrato. A ocorrência de tempestades eventuais pode ajudar na remoção ou no soterramento do óleo (MMA, 2002).

As áreas litorâneas classificados com o ISL 6 são compostas por praias de cascalho com declividade moderada e depósito de tálus; apresentam reflexão variável das ondas; exibem elevada permeabilidade do substrato (cascalho) ou substrato rochoso, com muitas reentrâncias; baixíssima trafegabilidade (Tabela 1; MMA, 2002). No litoral de Paraty, o extremo sul da Prainha (Figura 3I e 6) e o extremo norte da praia de Taquari (Figura 5) são exemplos de áreas representadas pelo ISL 6. 
Ana Beatriz Pinheiro, André Luiz Carvalho da Silva

Análise da sensibilidade ambiental do litoral de Paraty (Estado do Rio Janerio, Brasil) a potenciais derramamentos de óleo.

Figura 6. Mapa de Índice de Sensibilidade Ambiental do Setor Central.

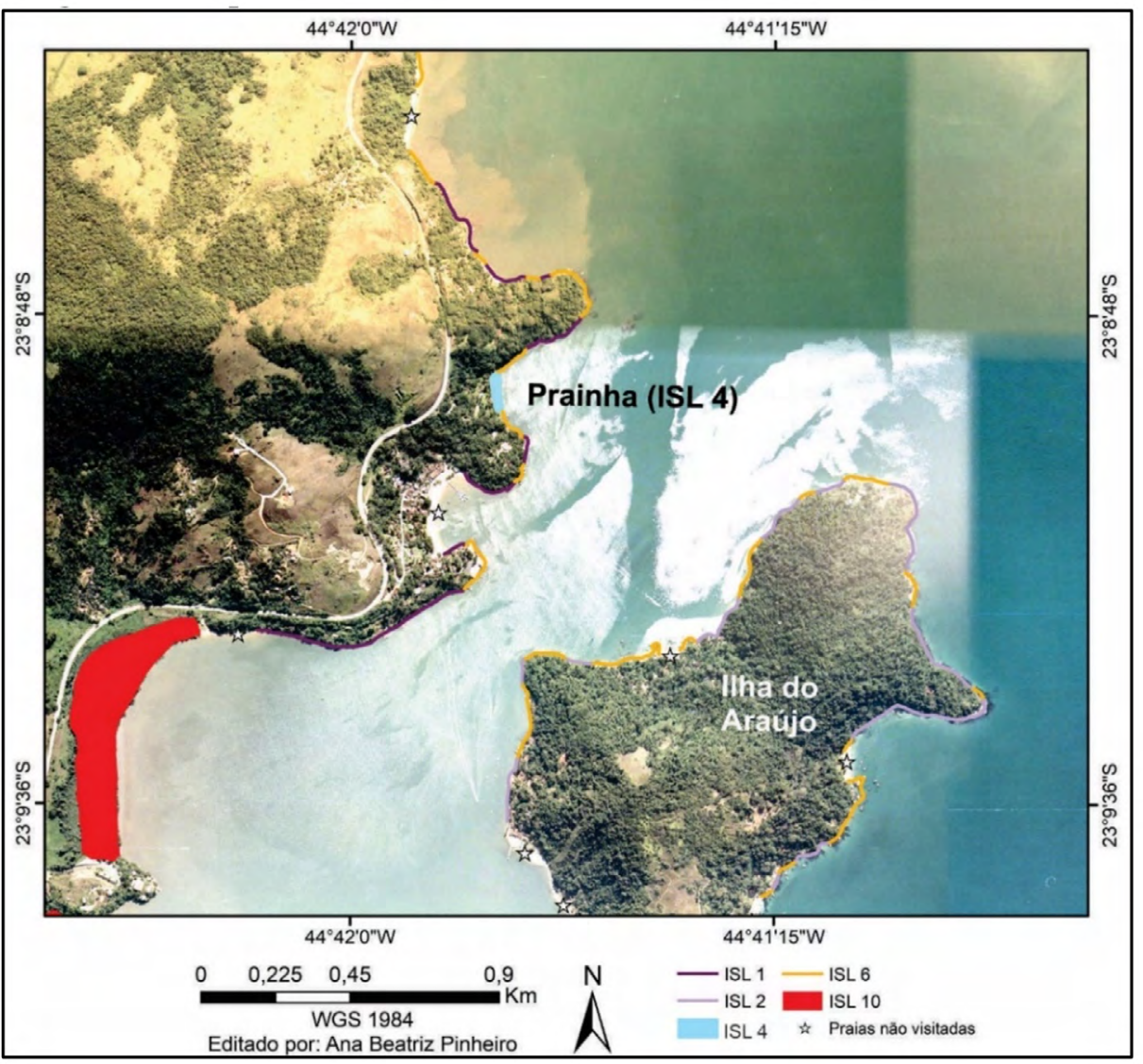

Fonte: Elaboração própria.

Os ambientes com o ISL 10 são caracterizados por brejo salobro ou de água salgada e manguezais; trata-se de ambientes de baixa energia, com substrato plano, lamoso a arenoso e declividade muito baixa (cerca de $3^{\circ}$ ); os sedimentos são moles e de baixa trafegabilidade, saturados pela água, com baixa permeabilidade, a não ser pela presença de orifícios feitos por animais (bioturbação) (Tabela 1; MMA, 2002).

Em Paraty, as áreas com ISL 10 correspondem ao setor norte da praia de Jabaquara (Figura 3L e 7), áreas de manguezal, identificadas no interior da Baía de Paraty; o manguezal localizado nas áreas adjacentes à barreira 
Figura 7. Mapa de Índice de Sensibilidade Ambiental do Setor Sul.

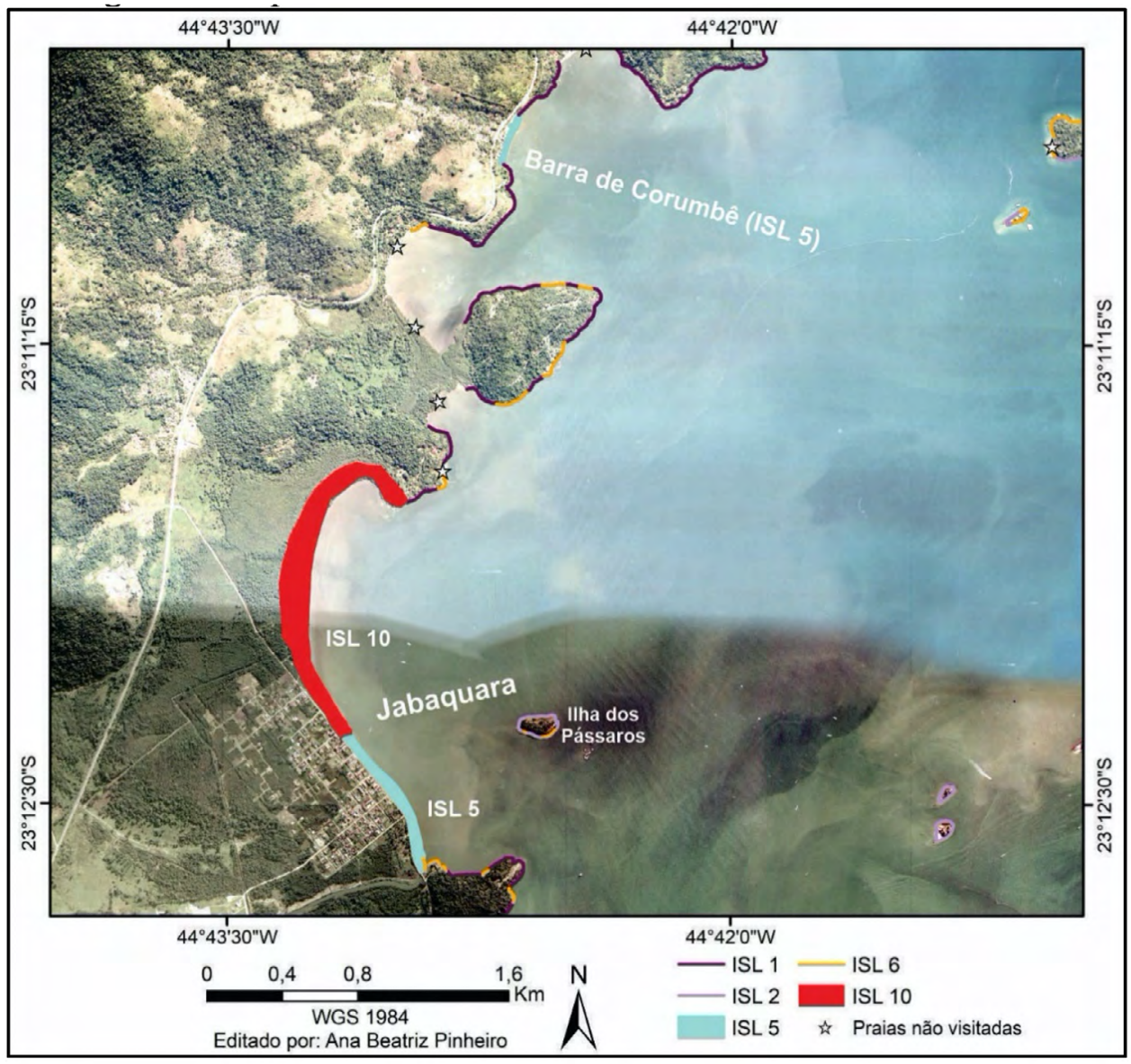

Fonte: Elaboração própria.

arenosa, em Taquari (Figura 3K e 5); e trechos mais interiores das áreas conhecidas como Saco do Fundão e Saco de Mamanguá (Figuras 2).

A penetração do óleo nesses ambientes é limitada pelos sedimentos saturados de água; há uma possibilidade de cobertura direta da vegetação pelo óleo na zona de intermaré, o que pode sufocar os organismos e impactar a biota; a remoção natural ocorre de forma lenta, devido aos baixos níveis de energia desses ambientes; constituem os hábitats mais sensíveis devido à elevada riqueza e valor biológico; o substrato mole dificulta a 
limpeza, e qualquer esforço nesse sentido pode introduzir o óleo nas camadas mais internas e agravar o dano.

O processo de limpeza por meio de maquinários é considerado inadequado em função da característica lamosa do substrato. São poucas as técnicas de limpeza disponíveis para remediar essas áreas atingidas por óleo e, além disso, pouco se conhece sobre a eficiência e os danos adicionais que a aplicação que determinados procedimentos podem gerar nesses ambientes (CETESB; 2007).

A comparação entre os resultados obtidos neste estudo com as Cartas de Sensibilidade Ambiental a Derramamentos de Óleo (Cartas SAO) Táticas e Estratégicas, elaboradas pelo MMA no ano de 2007 para a Bacia de Santos, permite observar algumas divergências em relação aos ambientes estudados. As praias de São Gonçalo, Barra de Corumbê e Jabaquara (setor sul) foram caracterizadas neste estudo com o ISL 5, diferentemente da classificação apresentada pelo MMA (2007), que considera essas praias como sendo de ISL 4.

Cabe destacar que, neste trabalho foram classificadas apenas as praias visitadas nesta pesquisa, com base na caracterização morfológica e sedimentar das mesmas. As demais praias ao longo do litoral de Paraty não foram classificadas devido à ausência de dados sobre à morfologia e tipo de materiais predominantes.

Entretanto, estas praias podem ser consideradas como de sensibilidade ambiental variando entre 3 a 6 . Os depósitos de tálus e enrocamentos mapeados em quase todo o litoral e classificados neste estudo como ISL 6, são incluídos na categoria costões rochosos e classificados com o ISL 1 e 2 pelo MMA (2007). Provavelmente, tais divergências possam ser o resultado da utilização de escalas distintas de análise.

Os órgãos competentes, acredita-se que priorizam o atendimento a uma área mais abrangente, o que impede um trabalho de maior detalhamento e caracterização dos aspectos físicos relacionados aos diversos ambientes costeiros, como o que foi realizado nesse estudo, por meio de visitas de campo às áreas aqui classificadas.

Outro motivo que tende a dificultar a classificação dos ISL, refere-se a dificuldade de acesso aos locais a serem monitorados, como ressaltado também por Gherardi et al. (2008). Alguns municípios litorâneos que margeiam a Bacia de Santos (Moriak, 2003), na qual Paraty está inserida, 
concentra a maior população humana do litoral brasileiro, com inúmeras propriedades privadas, residências e determinados usos comerciais que, de certa forma, acabam limitando o acesso a algumas áreas (Gherardi et al., 2008). Na área de estudo esse acesso é também dificultado pela inexistência de estradas ou trilhas por terra para alguns trechos do litoral, sendo o acesso possível apenas por meio de pequenas embarcações.

\section{Vulnerabilidade ambiental do litoral de Paraty}

Os impactos gerados por um derrame de óleo podem ser minimizados com ações emergenciais rápidas se houver um conhecimento prévio dos ambientes e ecossistemas que integram a área atingida. O litoral de $\mathrm{Pa}$ raty, devido a sua localização (uma parte abrigada e outra oceânica) e em função da diversidade de ambientes (praias, manguezais e costões), exibe uma sensibilidade ambiental complexa quanto aos efeitos de um eventual derrame de óleo.

Essa complexidade de ambientes aponta para diferentes níveis de sensibilidade, que tendem a variar bastante ao longo de toda a extensão da costa, com ISL variando desde 1 (menor sensibilidade à poluição) até 10 (áreas mais sensíveis). Essa diversidade nos níveis de sensibilidade ambiental à poluição por óleo foi igualmente relatada por Baptista (2017) para o litoral da Ilha Grande, também localizado na Baía da Ilha Grande, a leste da área de estudo; e por Pincinato (2007), que verificou a mesma diversidade na sensibilidade em São Sebastião e Caraguatatuba, litoral norte de São Paulo.

A essa sensibilidade somam-se as diferentes formas de uso e ocupação existentes num determinado litoral, que o torna mais vulnerável, principalmente quando se considera também a rica biodiversidade e geodiversidade associada às unidades de conservação. A Baía da Ilha Grande foi caracterizada por Creed et al. (2007) como um ambiente rico em espécies bênticas e de peixes, tanto recifais quanto de praias arenosas.

No litoral de Paraty, há um número elevado de Unidades de Conservação, o que é um indicador da alta diversidade e relevância ambiental desse local. As Unidades de Conservação são consideradas, segundo o Instituto Estadual do Ambiente (INEA, 2015), áreas prioritárias diante de um eventual desastre ambiental. O nível de importância que algumas atividades e usos têm para uma determinada localidade também representa um fator de grande relevância na determinação da vulnerabilidade de um 
litoral. Algumas cidades litorâneas, como é o caso de Paraty, tem o turismo como uma de suas mais importantes atividades econômicas que, em muitos casos, representa a principal fonte de renda para a população local.

Com base nos critérios de classificação estabelecidos pelo MMA (2007) são considerados como de baixa sensibilidade os ambientes associados aos índices (ISL) de 1 a 4; sensibilidade média, aquelas áreas para as quais foram atribuídos os índices entre 5 e 8; e de alta sensibilidade os ambientes com ISL 9 e 10. Os ambientes de menor sensibilidade são representados pelas áreas rochosas nas enseadas e ilhas ao longo do litoral.

As áreas superiores dos costões rochosos (ISL 1 e 2) geralmente não são alcançadas e lavadas pela ação das ondas e marés, o que pode causar a contaminação da fauna e flora presentes nos costões. Diversos são os métodos de limpeza disponíveis para minimizar a contaminação por óleo nos costões (CETESB; 2007), no entanto, a maioria prioriza somente a remoção física do óleo, não considerando seus impactos biológicos.

As maiores sensibilidades à poluição por óleo (ISL 10) identificadas na área de estudo, correspondem aos manguezais localizados em diversos trechos do litoral de Paraty, como no setor norte da praia de Jabaquara, Taquari, Saco do Fundão e Saco de Mamanguá (Figura 2, 5, 6 e 7). Esses locais, tornam-se ainda mais vulneráveis, quando se considera que são ambientes com alta biodiversidade; apresentam uma baixa capacidade de regeneração, pois estão em locais relativamente abrigados da incidência das ondas e de difícil acesso.

As técnicas de limpeza disponíveis para remediar áreas de manguezais atingidas por óleo são poucas e, além disso, pouco se conhece sobre a eficiência e os danos adicionais que a aplicação de determinados procedimentos pode gerar nesses ambientes (CETESB; 2007).

As praias de Paraty, com sensibilidade entre baixa e média, possuem grande relevância para a população local. As atividades ligadas ao turismo representam cerca de $80 \%$ da fonte de renda do município (Benchimol, 2007; Padilha, 2016), que oferece aos visitantes belas praias, inúmeras atividades culturais, hospedagem, gastronomia, passeios náuticos e terrestres, etc. As medidas a serem adotadas por ocasião de um eventual derramamento de óleo devem, inevitavelmente, considerar a sazonalidade relacionada ao fluxo de turistas nesse litoral, já abordada por autores como Romero (2009) \& Gurgel (2016). A concentração de turistas, na maioria 
das vezes, intensifica-se no verão, período de férias escolares e feriados. Nesses momentos, a quantidade de pessoas no município e as atividades ligadas ao turismo, aumentam consideravelmente, o que implica num número maior de variáveis a serem consideradas na mediação de um eventual desastre e contaminação por óleo no litoral de Paraty.

Diversos estudos chamam a atenção para as variações sazonais que ocorrem no perfil praial, considerada um aspecto de grande relevância para a compreensão da sensibilidade ambiental das praias (Wieczorek, 2006; Pincinato, 2007; Poletto \& Batista, 2008; Romero et al., 2011 e Baptista, 2017; Baptista et al., 2019). As praias são ambientes muito dinâmicos e apresentam mudanças constantes na declividade, topografia e granulometria (Carter, 1988; Friedman et al., 1992). Essas mudanças são mais evidentes durante a ocorrência de ressacas, quando as ondas de tempestade podem alcançar porções mais internas da faixa de areia (Carter, 1988; Friedman et al., 1992), como verificado em algumas praias abrigadas de Paraty, por Pinheiro (2018). Tais mudanças podem interferir no comportamento e no impacto do óleo sobre as praias (MMA, 2002). Neste sentido, e com base no ISL e na identificação dos principais usos observados, as praias de Jabaquara e São Gonçalo foram consideradas as mais vulneráveis, por apresentarem ISL 5 e por serem as mais frequentadas por turistas ao longo do ano.

A poluição por um eventual derramamento de óleo no litoral de $\mathrm{Pa}$ raty tende a ser mais severa na parte mais interna e, consequentemente, mais abrigada da Baía da Ilha Grande, devido a hidrodinâmica ser menos intensa nessa área. Como relatado por Muehe et al. (2006) \& Godoi et al. (2011), as ondas que chegam ao interior da baía, principalmente as de sudoeste, podem ser barradas devido a configuração da linha de costa.

Neste caso, os ambientes localizados dentro dessa baía, uma vez afetados por um evento dessa natureza, necessitariam de um tempo maior para se restabelecer de forma natural, o que faz desta uma área prioritária à conservação. Tais condições diferem substancialmente quando se considera o extremo sul do litoral de Paraty (como em Trindade), voltado para mar aberto e, consequentemente, exposto à incidência direta de ondas de alta energia.

A direção e a intensidade dos ventos, assim como as condições de maré e correntes no momento do desastre, são fatores que influenciam no 
transporte do óleo, pois interferem diretamente no padrão de circulação das águas superficiais dentro da baía e no alcance de uma eventual mancha de óleo sobre a praia e demais ambientes. Duque et al. (2008) apresentaram um modelo de circulação das águas superficiais da Baía da Ilha Grande, considerando ventos provenientes de NE e SO, e condições de marés de quadratura e sizígia.

Os autores chamam a atenção para a existência de uma forte corrente formada no corredor entre a Ilha Grande e a Baía de Sepetiba, o que tende a dificultar a mistura de água proveniente de cada uma das baías. Santos et al. (2018) chamam a atenção para a necessidade de se considerar a taxa de renovação das águas dento das baías. A taxa de renovação das águas dentro das baías de Ilha Grande e Sepetiba é maior sob condição de tempestade, devido a maior alcance da maré e, sobretudo da passagem ocasional de frentes frias; quando há uma maior entrada das águas oceânicas na baía.

Nessas condições, o transporte tende a ser maior de leste para oeste, o que contribui para uma maior renovação das águas da Baía de Ilha Grande. Um eventual desastre possivelmente causará mais impactos dentro da baía sob condição de mar calmo, devido à baixa renovação das águas, contribuindo para que o óleo derramado fique por um tempo maior nas áreas mais abrigadas que são mais sensíveis.

A poluição dos ambientes litorâneos por óleo no litoral de Paraty pode ocorrer a partir de duas fontes em potencial: (1) as atividades ligadas à extração e transporte de petróleo na região e (2) as atividades náuticas voltadas para o turismo local. O crescente aumento das atividades no Terminal Petrolífero da Baía da Ilha Grande (TEBIG) é preocupante, pois aumenta também os riscos de acidentes envolvendo vazamento de óleo.

Simulações realizadas por Oliveira (2003), Oliveira \& Meyer (2006) mostram que um eventual derrame de óleo nas proximidades do TEBIG pode afetar o litoral de Paraty. Os autores sugerem que durante um momento de calmaria e sobre a influência de ventos de sudeste, uma eventual mancha de óleo tende a ser direcionado para a região interna da Baía da Ilha Grande (Oliveira, 2003; Oliveira \& Meyer, 2006).

Esse cenário é preocupante, principalmente quando se considera que os vento provenientes do quadrante sudeste são predominantes na maior parte do ano neste litoral. Além disso, danos ambientais associados a derramamento de óleo já ocorreram na região em 2000 e 2002, onde foram 
derramados 4 e 16 mil litros de óleo, respectivamente, ambos por acidentes com navios.

De acordo com Oliveira (2003), o primeiro acidente aconteceu em 31 de agosto de 2000, com um navio no terminal; um dia depois do ocorrido, a mancha se espalhou pelos costões próximos ao terminal e se aproximou da Ilha Grande. Em 13 de maio de 2002, houve um vazamento de óleo cru (considerado leve); os costões e algumas praias próximas ao terminal foram atingidos e as boias de proteção empregadas na contenção do óleo não conseguiram evitar a contaminação do litoral.

O histórico de desastres de grandes proporções envolvendo derramamentos de óleo é preocupante no Brasil e no mundo. Um dos maiores desastres com vazamento de óleo no litoral brasileiro ocorreu na Baía de Guanabara em 18 de janeiro de 2000. Na ocasião, ocorreu o vazamento de aproximadamente 1,3 milhão de litros de óleo, devido a uma falha no sistema de controle de rompimento de um dos oleodutos da Refinaria Duque de Caxias (estado do Rio de Janeiro). O óleo derramado foi espalhado na Baía de Guanabara causando sérios danos à biodiversidade da fauna e flora; vários ecossistemas às margens da baía foram afetados, dentre eles a Área de Preservação Ambiental (APA) de Guapimirim, um manguezal, berçário para diversas espécies; cerca de 23 praias foram atingidas; muitos costões no interior da baía foram também atingidos. Além dos impactos ambientais, houve grandes prejuízos econômicos para o turismo e para os cerca de 30 mil pescadores locais. Houve impactos também na produtividade da Baía de Guanabara, que segundo estimativa da Federação dos Pescadores do Estado do Rio de Janeiro, caiu em mais de 90\% após o acidente; mesmo depois de 14 anos, os pescadores ainda sofrem com as consequências do desastre (SEMADS, 2001; Sousa et al., 2013). Conforme ressaltado por Soares et al. (2006), a área de manguezal afetada pela presença do óleo ainda não havia se recuperado completamente 5 anos após o derramamento ocorrido na Baia de Guanabara. Para Soares et al. (2006), o tempo necessário para a recuperação de um manguezal pode variar muito de local para local, segundo as características ambientais de cada região e da natureza do evento. No litoral de Paraty, a grande quantidade de manguezais distribuídos ao longo de todo litoral abrigado, tende a dificultar a definição de áreas prioritárias para a proteção e o estabelecimento de áreas de sacrifício no interior da Baía da Ilha Grande. 
Outro acidente de grandes proporções ocorreu em 2010 no Golfo do México (Estados Unidos), onde cerca de 4,9 milhões de barris de petróleo foram liberados no ambiente marinho, segundo McCrea-Strub et al. (2011) e Farber (2014). Esse desastre foi responsável pela contaminação de diversas áreas, causando a mortandade de algumas espécies e desequilíbrio de diversos ecossistemas costeiros e marinhos; gerou também um prejuízo de cerca de 247 milhões de dólares.

No ano de 2019, um derramamento de óleo ocorrido a algumas centenas de quilômetros da costa brasileira atingiu toda Região do Nordeste chegando também no Sudeste brasileiro, desde o estado do Maranhão até o extremo norte do Rio de Janeiro, totalizando 11 estados atingidos e 999 localidades afetadas pelo óleo (IBAMA, 2020). Várias cidades nordestinas foram afetadas e tiveram grandes prejuízos econômicos e ambientais, cujas dimensões ainda não foram devidamente quantificadas.

O turismo no litoral de Paraty é realizado, em grande parte, por pequenas embarcações que partem do píer localizado no Centro Histórico em direção as diversas praias e ilhas da região. Essas embarcações de pequeno porte (traineiras, escunas e lanchas) trafegam pela baía em grande quantidade e representam uma ameaça para o litoral, tendo em vista que cada uma delas dispõe de uma quantidade significativa de óleo com potencial para causar danos ambientais. Acidentes com pequenas e médias embarcações quando ocorrem tendem a liberar o combustível e o óleo retido no motor que, a depender da quantidade, pode comprometer o equilíbrio dos ecossistemas litorâneos e marinhos e, até mesmo, oferecer risco para os banhistas. Um acidente ocorrido no litoral de Maricá em 2014, causou o derramamento de cerca de 1,6 mil litros de óleo e afetou o turismo na região, causando a interdição de algumas praias (PORTAL G1, 2015).

Segundo informações obtidas por Begossi et al. (2009), Paraty é uma região bastante produtiva e local de passagem de peixes migratórios, o que faz desta uma área de elevado potencial para a pesca e, consequente fonte de renda para a população local. No total, existe mais de 800 pescadores tradicionais em Paraty, distribuídos em diferentes localidades (Trindade, Praia do Sono, Ponta Negra, Cajaíba, Saco do Mamanguá, Paraty-Mirim, Ilha do Algodão, Ponta Grossa, centro de Paraty, Ilha do Araújo, Praia Grande, São Gonçalo e Tarituba). Um acidente com derramamento de óleo na Baía da Ilha Grande, principalmente àqueles considerados como 
de grandes proporções, pode impactar severamente a economia turística e pesqueira da região, que é conhecida nacional e internacionalmente pelo elevado potencial turístico, além de abrigar dezenas de comunidades de pescadores artesanais.

\section{Conclusões}

O litoral de Paraty possui diversos ambientes com uma rica biodiversidade, com costões rochosos, praias e manguezais; com a maior parte de sua área abrigada dentro da Baía de Ilha Grande. Os ISL 1 e 2 foram atribuídos as áreas rochosas nas enseadas e ilhas ao longo do litoral. As praias exibem diferenças significativas no tocante à extensão, orientação, morfologia e textura dos sedimentos; consequentemente, os índices de sensibilidade ambiental a eventuais derramamentos de óleo variam bastante: o ISL 4 foi estabelecido para a Prainha, Taquari e São Gonçalinho; o ISL 5 compreende as praias de Jabaquara (setor sul), Barra de Corumbê e São Gonçalo. Os depósitos de tálus e enrrocamentos foram classificados com o ISL 6. As áreas de manguezais e a planície lamosa no extremo norte de Jabaquara representam as áreas de maior sensibilidade litorânea (ISL 10). Os índices encontrados atingem os dois extremos dessa classificação, variando de 1 a 10 , perpassando pelos níveis intermediários 4,5 e 6 . Tal fato decorre da grande variedade de ambientes na paisagem costeira do litoral estudado. As praias de Paraty que não foram estudadas e que, consequentemente, não foram classificadas quanto ao ISL, podem ser consideradas entre ISL 3 e 6, a depender das características geológicas e geomorfológicas das mesmas.

Apesar da grande importância ambiental de Paraty, com diversas Unidades de Conservação, da existência de comunidades pesqueiras tradicionais e da forte dependência das atividades ligadas ao turismo, algumas transformações observadas neste litoral e na região causam preocupações. Dentre elas, o aumento da exploração e extração petrolífera na Bacia de Santos, a proximidade com o Terminal Petrolífero da Baía da Ilha Grande (TEBIG), bem como, o aumento do tráfego de pequenas e médias embarcações vinculadas à atividade turística na região.

A definição de áreas prioritárias para ações de emergência e de sacrifício no litoral de Paraty se constitui numa tarefa difícil de ser adequadamente realizada, por diversos fatores, como: (1) grande diversidade de 
ambientes ao longo de toda a extensão da costa e com diferentes níveis de sensibilidade; (2) a quase totalidade do litoral está geograficamente abrigado dentro da Baía da Ilha Grande; (3) grande número de áreas pertencentes a Unidades de Conservação e com uma rica biodiversidade; (4) diferentes formas de uso e ocupação do litoral, voltados em grande parte para as atividades ligadas ao turismo e pesca na região. Neste sentido, uma contaminação por óleo tende a causar sérios danos ambientais, sociais e econômicos para a cidade de Paraty e seu entorno.

\section{Agradecimentos}

O presente estudo integra resultados obtidos ao longo de um monitoramento desenvolvido junto ao Programa de Pós-Graduação do Departamento de Geografia da Faculdade de Formação de Professores da Universidade do Estado do Rio de Janeiro e ao Programa de Pós-Graduação em Dinâmica dos Oceanos e da Terra da Universidade Federal Fluminense. Agradecimentos a Fundação de Amparo à Pesquisa do Estado do Rio de Janeiro (FAPERJ) pela bolsa concedida à estudante de mestrado. Ao Grupo de Estudos Costeiros (GECOST) da FFP-UERJ por todo o apoio dado ao longo da realização desse trabalho.

\section{Referências}

Amador, E. S. (1997). Baía de Guanabara e ecossistemas periféricos: Homem e Natureza. Rio de Janeiro, Reproarte Gráfica e Editora. Baptista, E. C. S. (2017). Sensibilidade ambiental do litoral da Ilha Grande (Angra dos Reis, RJ) a eventos de derramamento de óleo. Dissertação de Mestrado em Geografia - Universidade do Estado do Rio de Janeiro, p.112.

Baptista, E. C. S., Silva, A. L. C., Abuchacra, R. C.; \& Pinheiro, A. B. (2019). Sensibilidade ambiental do litoral da Ilha Grande (Angra dos Reis, RJ) a potenciais desastres causados por derramamento de óleo. Revista Brasileira de Geografia Física, 12 (07), pp. 2470-2488.

Begossi, A., Lopes, P. F. \& Oliveira L. E. C. (2009). Diagnóstico Socioambiental das comunidades de Pescadores Artesanais da Baía de Ilha Grande, R.J, p.259. 
Benchimol, M. F. (2007). Gestão de unidades de conservação marinhas: um estudo de caso da área de proteção ambiental da Baía de Paraty - RJ. Dissertação (Mestrado em Geografia) - Universidade Federal do Rio de Janeiro, p.113.

Boulhosa, M. B. M. \& Souza Filho, P. W. M. (2009). Reconhecimento e mapeamento dos ambientes costeiros para geração de mapas de ISA ao derramamento de óleo, Amazônia Oriental. Revista Brasileira de Geofísica (27), pp. 23-37.

Bowman, D., Rosas, V. \& Pranzini, E. (2014). Pocket beaches of Elba Island (Italy) e Planview geometry, depth of closure and sediment dispersal. Journal Estuarine, Coastal and Shelf Science (138), pp. 37-46.

Carter, R. W. G. (1988). Coastal Environments: An Introduction to the Physical, Ecological and Cultural Systems of Coastlines. 1. ed. London: Academic Press.

Castro, A. F., Souto, M. V. S., Amaro, V. E. \& Vital, H. (2003). Desenvolvimento e aplicação de um banco de dados geográficos na elaboração de mapas da morfodinâmica costeira e sensibilidade ambiental ao derramamento de óleo em áreas costeiras localizadas no Estado do Rio Grande do Norte. Revista Brasileira de Geociências (33), pp. $53-64$.

CETESB. (2007). Companhia Ambiental do Estado de São Paulo. Ambientes costeiros contaminados por óleo: Procedimentos de Limpeza - Manual de Orientação. Secretaria de Estado do Meio Ambiente. São Paulo, p.119.

Creed, J.C., Oliveira, A.E.S., Pires, D.O., Figueiredo, M.A.O., Ferreira, C.E.L., Ventura, C.R.R., Brasil, A.C.S., Young, P.S., Absalão, R.S., Paiva, P.C., Castro, C.B. \& Serejo, C.S. (2007). RAP Ilha Grande um Levantamento da Biodiversidade: Histórico e Conhecimento da Biota. In: Creed, J. C., Pires, D. O. \& Figueiredo, M. A. O. (Org.), Biodiversidade marinha da Baía da Ilha Grande. Editora MMA/SBF, Brasília, pp. 41-64.

Cunha, F. P. (2009). Mapeamento de Sensibilidade Ambiental a derramamentos de óleo na região costeira de Bertioga-SP. Dissertação de Mestrado em Geociências e Meio Ambiente - Universidade Estadual Paulista, p.98. 
Davidson-Arnott, R. (2010). Introduction to Coastal Process and Geomorphology. 1. ed. Londres: Cambridge University Press, p. 442.

Davis, JR. A. R. (1985). Coastal Sedimentary Environments. 3. ed. New York: Springer-Verlag, p.716.

Duque, M. M. S., Giacomini, J. \& Wasserman, J. C. (2008). Modelagem hidrodinâmica bidimensional da Baía da Ilha Grande e Baía de Sepetiba visando a subsidiar o plano local de desenvolvimento da maricultura. OADS - Organização Ambiental Para o Desenvolvimento Sustentável.

Farber, D. A. (2014). Lições do derramamento de óleo da plataforma Deepwater Horizon. Revista de Estudos Constitucionais, Hermenêutica e Teoria do Direito, vol. 1, 1-26.

Faria, A. P. (2018). Dinâmica geomorfológica da costa rochosa do Estado do Rio de Janeiro. Revista Brasileira de Geomorfologia, vol.19 (1), pp. 189-206.

Fragoso, M. R. (1999). Estudo numérico da circulação marinha da Região das Baías de Sepetiba e Ilha Grande (RJ). Dissertação de Mestrado do Instituto Oceanográfico, Universidade de São Paulo. p.144.

Friedman, G. M., Sanders, J. E. \& Kopaska-Merkel, D. C. (1992). Principles of Sedimentary Deposits: Stratigraphy and Sedimentology. 1. ed. Sydney: Maxwell Macmillan International.

Gherardi, D.F.M., Cabral, A. P., Klein, A. H. F., Muehe, D. C. E. H., Noernberg, M. A., Tessler, M. G. \& Sartor, S. M. (2008). Mapeamento da sensibilidade ambiental ao óleo da bacia marítima de Santos. Brazilian Journal of Aquatic Science and Technology, Itajai, v. 12 (2), pp. 11-31.

Gil-Agudelo, D. L., Nieto-Bernal, R. A., Ibarra-Mojica, D. M., GuevaraVargas, A. M. \& Gundlach, E. (2015). Índices de sensibilidad ambiental ante derrames de hidrocarburos en las áreas marinas y costeras de Colombia. Journal Ciencia, tecnología y futuro (6), pp. 17-22.

Godoi, V. A., Calado, L., Watanabe, B. W., Yaginuma, L. \& Pereira, M. B. (2011). Evento extremo de ondas na Baía da Ilha Grande: um estudo de caso. Boletim do Observatório Ambiental Alberto Ribeiro Lamego (5), pp. 28-44.

Gralato, J. C. A. (2016). Dinâmica de praia e vulnerabilidade às ondas de tempestades do litoral oriental da Ilha Grande (Angra dos Reis - RJ). 
Dissertação (Mestrado em Geografia) - Faculdade de Formação de Professores, Universidade do Estado do Rio de Janeiro, São Gonçalo, p.130.

Gurgel, F. O. M. (2016). Aplicações de modelagem hidrodinâmica para ações de resposta a incidentes de poluição por derrame de óleo: estudo de caso da Enseada dos Anjos em Arraial do Cabo-RJ. Dissertação (Mestrado em Engenharia Urbana e Ambiental) - Pontifícia Universidade Católica do Rio de Janeiro, Rio de Janeiro, p.167.

IBAMA. (2020). Instituto Brasileiro do Meio Ambiente e dos Recursos Naturais Renováveis: https:/www.ibama.gov.br/phocadownload/ emergenciasambientais/2020/manchasdeoleo/2020-01-15_LOCALIDADES_AFETADAS.pdf.

Instituto Estadual do Ambiente (INEA). (2015). Instituto Estadual do Ambiente. Diagnóstico do Setor Costeiro da Baía de Ilha Grande. Brasília, p.242.

Longarete, C., Dalinghaus, C. \& Abreu, J. G. N. (2016). Caracterização morfológica, hidrodinâmica e sedimentar das praias abrigadas Cardoso e Lagoa na Baía de Tijucas, Bombinhas - SC. Revista Brasileira de Geomorfologia, 17, pp. 1-17.

Mahiques, M. M. (1987). Considerações sobre os sedimentos de superfície de fundo da Baía da Ilha Grande, Estado do Rio de Janeiro. Dissertação de Mestrado do Instituto Oceanográfico, Universidade de São Paulo, p.139.

Martins, P. T. A.; Riedel, P. S.; \& Milanelli, J. C. C. (2013). Carta de sensibilidade ambiental ao óleo: origem, evolução e tendências. Revista do Centro de Ciências Naturais e Exatas - UFSM (35), pp. 163-175. McCrea-Strub, A., Kleisner, K., Sumaila, U. R., Swartz, W., Zeller, D. \& Pauly, D. (2011). Potential Impact of the Deepwater Horizon Oil Spill on Commercial Fisheries in the Gulf of Mexico. Fisheries Research, vol. 36 (7), pp. 1-12.

Medeiros, M. F. (2006). Estudos da sequência sedimentar holocênica das baías da ribeira e parati (Baía Ilha Grande - RJ) através de métodos sísmicos e análise de testemunhos. Dissertação de Mestrado em Geologia e Geofísica Marinha - Universidade Federal Fluminense, Niterói, p.126. 
Ministério do Meio Ambiente (MMA). (2002). Ministério do Meio Ambiente. Especificações e normas técnicas para elaboração de cartas de sensibilidade ambiental para derramamentos de óleo, p.107.

Ministério do Meio Ambiente (MMA). (2007). Ministério do Meio Ambiente. Atlas de sensibilidade ambiental ao óleo da Bacia Marítima de Santos. Brasília, p.116.

Mohriak, W. U. (2003). Bacias Sedimentares da Margem Continental Brasileira. Geologia, Tectônica e Recursos Minerais do Brasil. L. A. Bizzi, C. Schobbenhaus, R. M. Vidotti e J. H. Gonçalves (eds.) CPRM, Brasilia (1), pp. 87-94.

Moraes, A. C. R. (2007). Contribuições para a Gestão da Zona Costeira do Brasil: elementos para uma Geografia do litoral brasileiro. Ed. Annablume, p. 232.

Muehe, D., Lima. C. F. \& Lins-de-Barros. F. M. (2006). Erosão e progradação do litoral brasileiro. 1. ed. Brasília: MMA, pp. 1-360.

Muler, M., Romero, A.F., Riedel, P.S. \& Perinotto, R.R.C. (2011). Ações de resposta para emergência em caso de derrames de óleo no mar e proposta de implementação de sistema de informação voltado à sensibilidade ambiental para o litoral sul paulista Brasil. Revista de Gestão Costeira Integrada (4), pp. 397-407.

NOAA. (2007). Administração Atmosférica e Oceânica Nacional dos Estados Unidos. NOAA CELEBRATES. Environmental Sensitivity Mapping. Disponível em: <http://celebrating200years.noaa.gov/ foundations/esi_map/welcome.html\#intro>. Acesso em 12 de maio de 2019.

Oliveira, R. F. (2003). O comportamento evolutivo de uma mancha de óleo na Baia de Ilha Grande, RJ: modelagem, análise numérica e simulações. Tese de Doutorado em Matemática Aplicada - Universidade Estadual de Campinas, Campinas, p.95.

Oliveira, R. F. \& Meyer, J. F. C. A. (2006). A Elaboração de Cenários de Acidentes com Derrame de Óleo na Região do Terminal de Angra dos Reis, RJ: Modelagem, Análise e Simulação Computacional. The journal TEMA - Trends in Applied and Computational Mathematics (7), pp. 101-108. 
Padilha, M. N. (2016). Turismo, Patrimônio Histórico e Transformações Socioespaciais em Cidades Tombadas. O caso de Paraty. Revista Rosa dos Ventos - Turismo e Hospitalidade (8), pp. 1-16.

Perinotto, R. R. C., Riedel, P. S. \& Milanelli, J. C. C. (2010). Sensibilidade Ambiental ao derrame de óleo da linha de costa da Baía de Santos, SP - Brasil. Revista Brasileira de Cartografia, vol. 63 (4), pp. 501-514.

Pincinato, F. L. (2007). Mapeamento da sensibilidade ambiental a derramamentos de óleo para a região costeira de São Sebastião e Caraguatatuba, litoral norte de São Paulo (SP), com uso de modelagem em SIG de sistema especialista baseado em conhecimento e árvore de decisão. Dissertação de Mestrado em Geociências e Meio Ambiente - Universidade Estadual Paulista, Rio Claro, p.160.

Pinheiro, A. B. (2018). Geomorfologia de praias e sensibilidade ambiental no litoral de Paraty $(R J)$ à potenciais eventos de derramamento de óleo. Dissertação de Mestrado em Geografia - Universidade do Estado do Rio de Janeiro, p.141.

Poletto, C. R. B \& Batista, G. T. (2008). Sensibilidade ambiental das ilhas costeiras de Ubatuba, SP, Brasil. Revista Ambiente \& Água - An Interdisciplinary Journal of Applied Science, (3), nº 2, pp. 106-121.

PORTAL G1. (2015). Praia é interditada para retirada de barco com vazamento em Maricá, RJ. http://g1.globo.com/rj/regiao-dos-lagos/ noticia/2015/01/praia-e-interditada-para-retirada-de-barco-com-vazamento-em-marica-rj.html.

Pranzini, E., Rosas, V., Jackson, N.L. \& Nordstrom, K.F. (2013). Beach changes due to sediment delivered by streams to pocket beaches during a major flood. Geomorphology, pp. 36-47.

Rocha, T. C. F. (2009). Mapeamento da sensibilidade ambiental do litoral de Ubatuba - SP a vazamentos de petróleo. Dissertação de mestrado apresentada ao Programa de Pós-graduação em Geociências e Meio Ambiente da Universidade Estadual Paulista, p.129.

Rodrigues, S. W. P. \& Souza-Filho, P. W. M. (2012). Mapping of environmental sensitivity index to oil spill from landsat tm images: "a study case on the Amazon Coastal plain". Revista Brasileira de Geofisica, 30 (4), pp. 533-543. 
Romero, A. F. (2009). Mapa de vulnerabilidade ambiental ao óleo e cartas SAO. Trecho: Praia Grande - Ilha Comprida, litoral paulista. Tese de doutorado apresentada ao Programa de Pós-graduação em Geociências e Meio Ambiente da Universidade Estadual Paulista, p.125.

Romero, A. F., Riedel, P. S., Milanelli, J. C. C. \& Lammardo, A. C. R. (2011). Mapa de vulnerabilidade ambiental ao óleo - um estudo de caso na Bacia de Santos, Brasil. Revista Brasileira de Cartografia, vol.1, pp. 1-13.

Rosa. L. C. \& Borzone. C. A. (2008). Uma abordagem morfodinâmica na caracterização física das praias estuarinas da Baia de Paranaguá, sul do Brasil. Revista Brasileira de Geociências, 38 (2), pp. 237-245.

Santos, A. L. F., Ponte, L., Peixoto, R. S., Rosman, P. A. \& Rosman, P. C. C. (2018). Projeto Baías do Brasil. Relatório - Baías de Ilha Grande e Sepetiba-RJ. COPPE/UFRJ, p.42.

SEMADS. (2001). SECRETARIA DE ESTADO DE MEIO AMBIENTE E DESENVOLVIMENTO SUSTENTÁVEL. Bacias Hidrográficas e Rios Fluminenses Sintese Informativa por Macrorregião Ambiental. Rio de Janeiro, p.73.

Silva, A. L. C., C. A. Gralato, J, Brum, T. C. F., Silvestre, C. P., Baptista, E. C. S. \& Pinheiro, A. B. (2020). Dinâmica de praia e susceptibilidade às ondas de tempestades no litoral da Ilha Grande (Angra dos Reis -RJ). Journal of Human and Environment of Tropical Bays, 1, pp. 9-44.

Silva, I. R., Nascimento, H. M. \& Rebouças, R. C. (2009). Avaliação da sensibilidade ambiental das praias localizadas no Arquipélago Tinharé/Boipeba, Litoral Sul do Estado da Bahia. Geociências, v. 28 (2), pp. 193-201.

Silva, M. A. M., Silva, A. L. C., Santos, C. L., Silvestre, C. P., Antonio, R. V. M., Cunha, A. B. C., Gralato, J. C. A. \& Souza, R. D. (2016). Praias da Baía de Guanabara no estado do Rio de Janeiro. Revista Brasileira de Geomorfologia, 17 (2), pp. 205-225.

Soares, M. L. G., Junior, C. M. G., Cavalcanti, V. F., Almeida, P. M. M., Monteiro, A. S., Chaves, F. O., Estrada, G. C. D. \& Barbosa, B. (2006). Regeneração de floresta de mangue atingida por óleo na Baía 
de Guanabara (Rio de Janeiro, Brasil): resultados de 5 anos de monitoramento. Geochemica Brasiliensis, vol. 20 (1), pp. 1-15.

Sousa, L. G. R, Miranda, A. C. \& Medeiro, H. B. (2013). Impacto ambiental e socioeconômico do derramamento de óleo na Baía de Guanabara. IX Fórum Ambiental da Alta Paulista, v. 9 (2), pp. 94-108.

Souza, R. D. (2007). Contribuição à confecção de mapas de sensibilidade para as praias de Niterói - RJ (Baía de Guanabara). Trabalho de Conclusão de Curso (Graduação em Geografia) - Universidade Federal Fluminense, Niterói, p.74.

Wieczorek, A. (2006). Mapeamento de Sensibilidade a Derramamentos de Petróleo do Parque Estadual da Ilha do Cardoso - PEIC e Áreas do entorno. Dissertação de Mestrado em Geociências e Meio Ambiente - Universidade Estadual Paulista Júlio de Mesquita Filho, São Paulo, p.143. 